\title{
Design of a Mobile Brain-Training Tool for Seniors: Motivational Requirements
}

\author{
Donal O’Brien ${ }^{1}$, R. Benjamin Knapp ${ }^{1}$, Oonagh Thompson ${ }^{1}$, David Craig ${ }^{1}$ and \\ Suzanne Barrett ${ }^{1}$ \\ ${ }^{1}$ Queen's University Belfast
}

\begin{abstract}
The overall goal of this project is to design, develop, and validate a mobile phone-based 'brain training' software suite targeted at senior users, using iterative person-centered design methodologies, that will permit a subsequent clinical trial of cognitive stimulation efficacy known as the SONIC ${ }^{2} S$ Study (Stirling-Oregon-Northern Ireland-Chicago Cognitive Stimulation Study). The SONIC ${ }^{2} S$ Study will represent a long term (c. 15 year), very large scale $(n=12,000)$, embedded clinical trial that aims to definitively establish whether or not brain training acts to prevent dementia or cognitive decline. It is anticipated that participant compliance in such a study will be a significant concern. This study reports on a series of focus groups, usability studies and field trials which sought to identify the key motivational factors influencing seniors' engagement with mobile brain-training technology in order to inform the design of a bespoke tool which is acceptable / enjoyable to target users.
\end{abstract}

Keywords: User-centred design, brain-training, technology acceptance.

\section{INTRODUCTION}

Some work has been done previously on motivational factors underlying seniors' engagement with computer games. In a survey with 271 participants aged between 39 and 68, Pearce found socialising to be a strong motivation for digital game playing [1]. Challenge, i.e. the degree to which ones skills are tested, also emerges from the literature as an important motivating factor. For example, in a survey comparing adolescent and adult gamers, De Schutter and Malliet found challenge to be the highest ranked motive for playing amongst the older cohort [2]. Another prominent motivating factor for older users seems to be the game's perceived usefulness. For instance, in a series of semistructured interviews with 7 participants and a survey with 400 respondents over the age of 50, Woldberg found that seniors like puzzles because they 'are good for the brain' [3].

\section{METHOD}

\section{A. Participants}

Thirty-four participants $(23 \mathrm{~F}, 11 \mathrm{M}$. Median age range $60-$ 64) took part in four focus groups (FGs) lasting approximately 2 hours each. Participants were mainly recruited from seniors' groups in the north and south of Ireland between Nov '09 and May '10. Twenty-two (65\%) played puzzles (defined as word, number, memory, spatial, visual processing or reasoning games) at least weekly and 7 (21\%) never played. Twenty-one
$(62 \%)$ had been doing puzzles for longer than 10 years while $12(35 \%)$ used some form of computer-based platform to play.

\section{B. Procedure}

Prior to beginning, participants completed a background questionnaire and gave consent. Each FG consisted of three sub-sessions: an introductory session, a 'transitional activity' (where the participants were given 40 mins hands-on experience with commercially available brain training software) followed by a session in which key questions were asked. Mainly iPhones and iPods were used during the transitional activity, although the Nintendo DS, pc-based and Internet-based platforms were also employed. A range of commercially available brain training software was used. During the transitional activity participants recorded any motivational / de-motivational aspects that arose on a sheet. During the key questions session, discussions in relation to the games played during the transitional activity were steered according to these main questions: 1) Are there any aspects in particular that would (a) motivate you play again or (b) turn you off playing again? 2) Is there anything that could be added to these games that would compel you to play them more?

Following this, participants were given a sheet describing 9 prominent motivational factors discovered through a search of the literature in order to further stimulate the discussion. They were asked to consider the importance of each motivational factor in groups of two before discussing with the group as a whole. Following this, the discussion was guided by the following question: Which of the [nine] motivations, if any, do people think would be reasons to play if they were factored into computer-based puzzle games? Finally, the main points raised were summarized and put to the participants for agreement or correction.

Audio from the FGs was recorded. During the analysis, relevant comments were coded as either motivational or demotivational and further sub-categorized according to prominent themes such as 'challenge' or 'usability issues'. These comments were entered into SPSS along with a representative quote and counted to give a ranking of motivational and de-motivational factors. Finally, codings were rechecked and where appropriate, re-coded. 


\section{RESULTS}

Arising from the coding procedure, 237 motivational comments made up 19 motivational factors and 123 demotivational comments made up 15 de-motivational factors. Tables 1 and 2 below show the ranking of the top motivational / de-motivational factors.

TABLE I. RANKING OF MOTIVATIONAL FACTORS

\begin{tabular}{lcc}
\hline \hline \multicolumn{1}{c}{ Motivation } & Count & \% \\
\hline Challenge & 59 & $24.9 \%$ \\
Usefulness & 40 & $16.9 \%$ \\
Familiarity & 30 & $12.7 \%$ \\
Entertainment & 21 & $8.9 \%$ \\
Relaxation & 17 & $7.2 \%$ \\
Achievement & 15 & $6.3 \%$ \\
Ease of use & 14 & $5.9 \%$ \\
Other $(<5 \%)$ & 41 & $17.3 \%$ \\
Total & 237 & $100.0 \%$ \\
\hline \hline
\end{tabular}

Challenge was the highest ranked motivational factor across all FGs with $25 \%$ of all recorded comments. The majority of comments value challenge as a means to achievement: "I find them quite challenging. When I finish I think 'see if I can better that score"" - (p2, FG1).

Seventeen percent of all motivational comments related to perceived practical benefits or the need for such: "It could make you more alert and I think it's very important we keep ourselves in a certain condition" - (p13, FG2).

Thirteen percent of comments related to the need for games content that is familiar to users: "I enjoyed the math ones [games] better than matching shapes... I'm an accountant and numbers are my life..." - (p20, FG3).

TABLE 1. RANKING OF DE-MOTIVATIONAL FACTORS

\begin{tabular}{lcc}
\hline \hline \multicolumn{1}{c}{ De-Motivation } & Count & \% \\
\hline Usability issues & 34 & $27.6 \%$ \\
Poor communication & 19 & $15.4 \%$ \\
Too fast & 15 & $12.2 \%$ \\
Difficult & 8 & $6.5 \%$ \\
Social isolation & 8 & $6.5 \%$ \\
Time consuming & 7 & $5.7 \%$ \\
Other $(<5 \%)$ & 32 & 26.0 \\
Total & 123 & $100.0 \%$ \\
\hline \hline
\end{tabular}

Usability issues was the highest ranked de-motivational factor with $28 \%$ of all comments: "To me it wasn't stimulating, it was frustrating because... no matter what I did, it wouldn't accept anything..." - (p16, FG3).

The next highest ranked de-motivational factor (15\%) related to poor communication from the games, usually in the form of poor instruction: "Instructions - Why keep an eye on the time? No reason given. Felt uncertain about what to do." [comment from transitional activity] - (p28, FG3).

Twelve percent related to games being 'too fast': "I find they're very quick... if they were a bit slower they might be better for us..." - (p27, FG4).

\section{STUDY 2}

Output from the focus groups was used to inform the design of a 'brain training' application for the iPhone named 'Brain Jog'. The application consisted of 3 mini games designed to test 3 main areas of cognition: working memory, spatial ability and arithmetic ability.

Two field trials were run with Brain Jog in order to 1) observe any new motivational factors that might arise from longer exposure to the games 2) evaluate the design decisions made based on the output of study 1 and 3) inform future iterations. As a preliminary step, two usability studies were conducted motivated by previous research which has shown how usability issues can form significant barriers to technology acceptance [4]. Many issues were identified and addressed but are not reported here since they are not the main focus of this paper.

\section{FIELD TRIAL 1 - METHOD}

\section{A. Participants}

Six participants $(5 \mathrm{~F}, 1 \mathrm{M}$. Median age range $65-69)$ took part in the first field trial. Five of the participants had at least weekly experience with computers. The other had never used a computer. All 6 had never used a smartphone before. Four did puzzles at least $2-3$ times weekly and two rarely did puzzles. Participants were recruited from 2 Belfast-based seniors' groups.

\section{B. Procedure}

The first field trial ran for 1 week. On the first day, participants met at Queen's University Belfast for briefing and training. Participants completed a background questionnaire, gave consent and were each given one 2 nd generation iPod touch with Brain Jog installed to take home. Training lasted approximately 40 mins and gave an overview of essential iPhone techniques as well as an introduction to Brain Jog.

Participants were informed that the purpose of the study was to identify motivating and de-motivating aspects of the software. They were requested to play the games 'at their leisure' but to 'give it a fair go'. Each participant was provided with a diary and requested to record the reason they started and the reason they stopped for each time they played. At the end of the 7-day period, participants met again at Queen's for a focus group lasting approximately 2 hours. The focus groups were coded according to the same procedure in study 1 . 


\section{Measurement}

The games were equipped with purpose-built touch recording software that collected quantitative performance data (scores etc.) as well as keystroke data such as interaction timings. Also, a periodic post-game survey was built into the software that was designed to measure the users game experience based on a set of adjectives designed to measure optimal experiences in daily life [5] as per Csikszentmihalyi's theory of 'Flow' [6].

\section{FIELD TRIAL 1 - RESULTS}

The post-field-trial-FG-analysis yielded 80 motivational comments and 48 de-motivational comments. The need for 'feedback' arose as a new motivational factor ranked third with 14\% of comments: "I think it might be useful to know what the potential within the game is. I mean, I wasn't aware that there was a level 4 ... but that would have been an extra challenge had I known." - p3.

Ranked highest of the de-motivational factors was the new factor 'boring' with $29 \%$ of comments: "It's kind of monotonous doing the same thing [playing the same games]" p5.

This feeling of boredom is perhaps reflected in the median scores for users' post-game surveys: spatial game: $4.9(\mathrm{~N}=9)$, working memory game: $4.3(\mathrm{~N}=17)$ arithmetic game: $3.15(\mathrm{~N}$ $=16$ ) where 4 marked the midpoint on the scale.

A redesign of Brain Jog was informed by the output of the first field trial and a second field trial was conducted with the redeveloped software. Included in the redesign were a new word game and a module for providing feedback in relation to the users' progress.

\section{FIELD TRIAL 2 - METHOD}

\section{A. Participants}

Six male participants took part in the second field trial. Median age range was $75-79$. Three of the participants had at least weekly experience with computers. One had rarely and two had never used a computer. Four had never used a smartphone before, one used one daily and the other, rarely. One did puzzles daily, two rarely and 3 never. Participants were recruited from the "W Club", which is a men's club in Belfast.

Procedure and measurement were the same as for field study 1 except that the second field trial ran for 3 weeks and both the briefing / training session and the focus group were held on $\mathrm{W}$ club premises.

\section{FIELD TRIAL 2 - RESULTS}

The post-field-trial-FG-analysis yielded 85 motivational and 22 de-motivational comments. Challenge was the by far the highest ranked motivational factor with $44 \%$ of all comments. Social interaction was the next highest ranked motivational factor with $11 \%$ of all comments: "If it... could be played as a family or a group of people I certainly would be more involved in it." - p12.

Perhaps with longer exposure to the games, the solitary nature of playing became more apparent. However, it is difficult to draw definite conclusions since $11 \%$ here amounts to a total of 9 motivational comments.

The ratio of de-motivational to motivational comments was quite low at roughly 1:4. Nevertheless, the top two demotivational factors were 'difficult': and 'tiring' with 6 comments each: "When you found it so difficult and you were not really acquiring any skill from it, you didn't go back to it" p9, "Eyes getting sore" [Reason for stopping. Recorded from participant diary] $-\mathrm{p} 7$.

Median scores from the post-game surveys showed an increase in the quality of game experience: spatial game: 5.94 $(\mathrm{N}=24)$, working memory game: $5.00(\mathrm{~N}=15)$ arithmetic game: $6.00(\mathrm{~N}=19)$ word game: $4.94(\mathrm{~N}=12)$ where 4 marked the midpoint on the scale.

\section{DISCUSSION}

In terms of the first hour or so of play, users in this age group will be most motivated to engage with mobile puzzle game technology when it's perceived as providing a good challenge, of some practical benefit and is in some way familiar. Users will see usability issues, poor communication from the game and games that are inappropriately timed, i.e. too fast, as barriers to engagement. With additional time exposure to the games in the region of $1-3$ weeks, users may be motivated to engage if the game provides appropriate feedback in relation to progress and in some way facilitates social interaction.

\section{REFERENCES}

[1] C. Pearce, The Truth About Baby Boomer Gamers: A Study of OverForty Computer Game Players. Games and Culture, 3(2), 142-174. 2008.

[2] De Schutter, B. \& Malliet, S. (2009) "A Different or just an Older Breed of Gamer? The use of digital games in middle adulthood", Proceedings of the annual meeting of the international communication association (ICA), Chicago Marriott Downtown Magnificent Mile, Chicago, Illinois.

[3] Y. Woldberg, Profiling the Dutch senior gamer. Presentation at Meaningful Play 2008, East Lansing, Michigan, USA. 2008.

[4] F. Davis, "Perceived usefulness, perceived ease of use, and user acceptance of information technology". MIS Quarterly, (Sept.), pp.339, 319. 1989.

[5] G.D. Ellis \& J.E. Voelkl. "Measurement and analysis issues with explanation of variance in daily experience using the flow..." Journal of Leisure Research, 26(4), p.337. 1994.

[6] J. Nakamura \& M. Csikszentmihalyi, "The concept of flow". In C. R. Snyder \& S. J. López, eds. Handbook of positive psychology. Oxford University Press US, pp. 89 - 105. 2002. 